\title{
Enhancing Color Image Clustering using K-Means Method
}

\author{
Prof. Ziad Alqadi ${ }^{1}$, Dr. Ghazi M. Qaryouti ${ }^{2}$, Prof. Mohammad Abuzalata ${ }^{3}$, Prof. Yousf Eltous ${ }^{4}$ \\ Albalqa Applied University, Faculty of Engineering Technology, Jordan, Amman ${ }^{1,2,3,4}$
}

\begin{abstract}
Creating a color image features is an important and vital task, because these features can be used in a color image recognition system, so decreasing the effort of clustering, and decreasing the feature extraction time will lead to better and efficient color images recognition system. In this paper research we will investigate how using color image histogram will enhance the recognition system, without doing any changes in the accuracy and uniqueness of the kmeans method of features extraction.
\end{abstract}

Keywords: Color image, histogram, resolution, features, k-means, cluster, centroid, extraction time, and speed up

\section{INTRODUCTION}

Digital image is one of the most important type of digital data, it is now widely used in many vital application such security [1], [2], [3] systems using cryptography [4] and steganography [5], [6], computer systems identification such as banking systems, robotics etc.

Digital image are usually represented by 2D matrix [7], [8] (gray image), or 3D matrix (color image) [9], [10]. The intersection of row and column is called a pixel and it takes the value between 0 and 255 for a gray image as shown in figure 1.

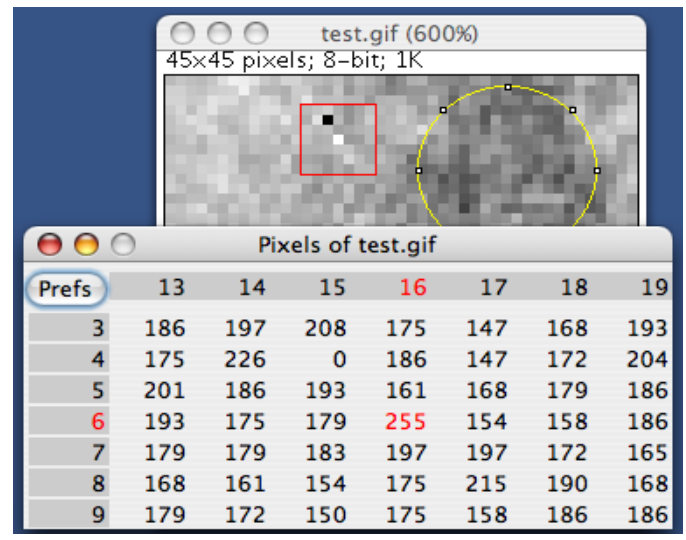

Figure 1: Gray image and pixels

Color image matrix consists of three 2D matrix[11] : the first one represents the red color, the second one represents the green color, while the third one represent the blue color, each pixel has a 3 color value as shown in fig 2 and 3 [12], [13].

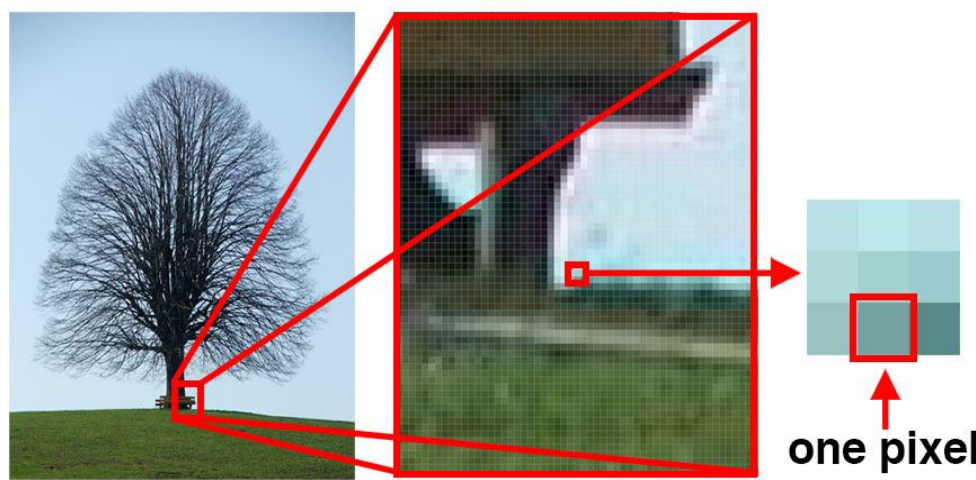

Figure 2: Color pixel 
Vol. 9, Issue 1, January 2020

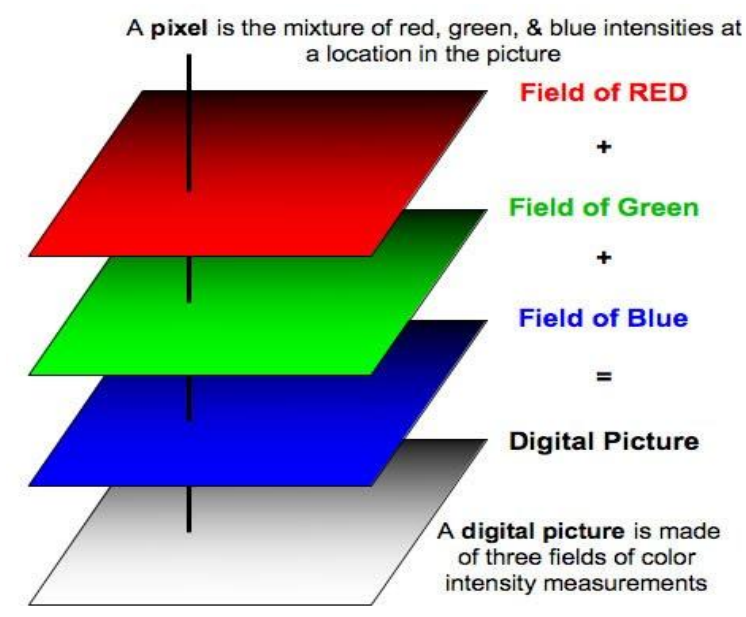

Figure 3: Mixing colors

Color images can be represented a histogram. An image histogram is a graph to show how many pixels are at each scale level, or at each index for the indexed color image [14], [15]. The histogram contains information needed for image equalization, where the image pixels are stretched to give a reasonable contrast.

For the gray image the histogram is a one column matrix with 256 elements, each index in this matrix points to the total repetition of the gray value in the image. For color images, each color channel can be represented by a histogram, and here we can add the tree histograms to find the total histogram, or we can covert the color image to gray one, and after that we can calculate the histogram as shown in figures 4 and 5.
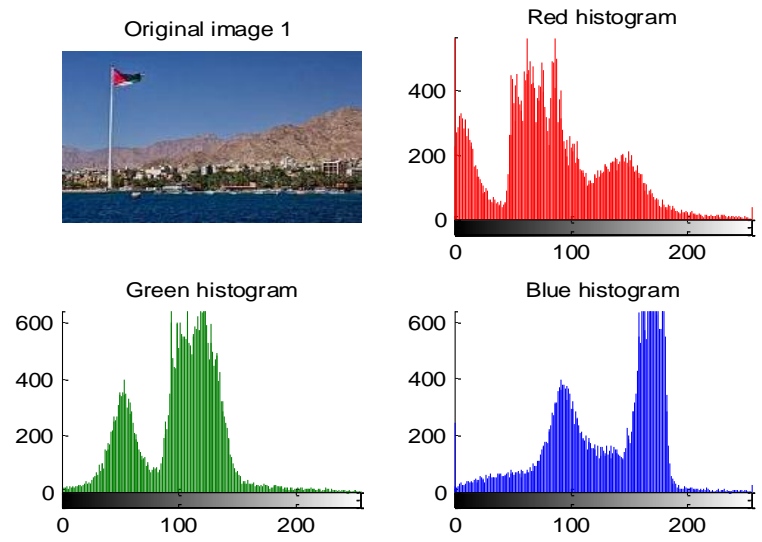

Figure 4: Color image and colors histogram
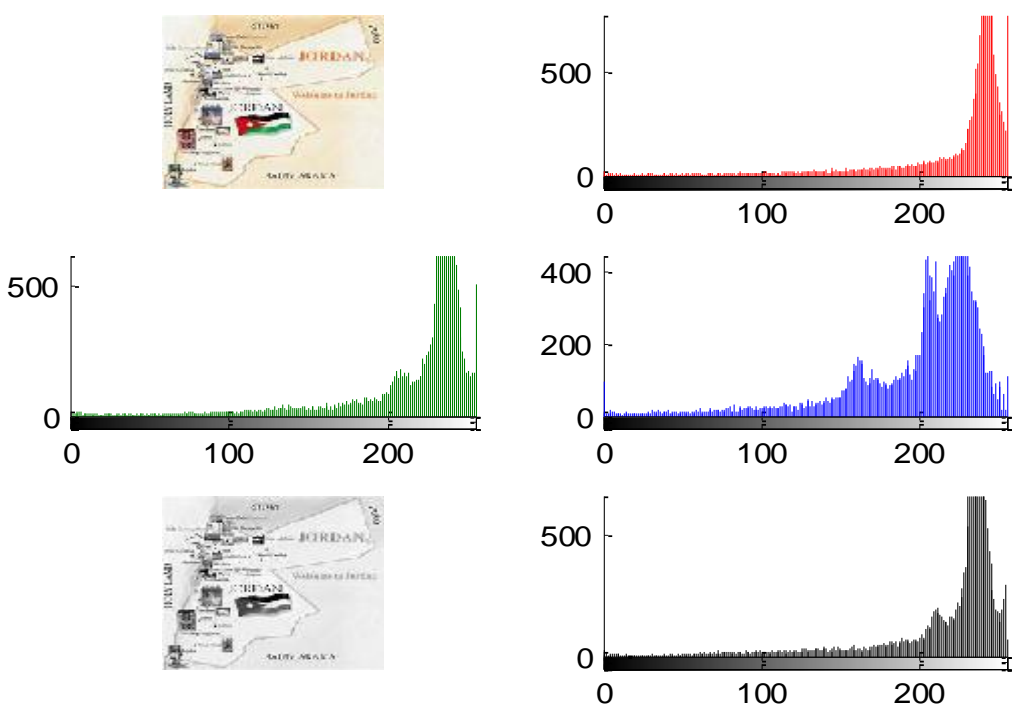

Figure 5: Equivalent gray image histogram 


\section{IMAGE FEATURES EXTRACTION}

Image resolution refers to the number of pixels in an image. Resolution is identified by the number of rows and columns in the image matrix as well as the total number of pixels in the image, for example, an image that is 2048 pixels wide and 1536 pixels high (2048x1536) contains (multiply by 3) 9437184 pixels (or 9.4 Mega pixels), we can call it a 9.4 mega pixel image, so color images always have a huge number of pixels, this leads of adding difficulties in the process of matching the images pixel by pixel.

For the process of image identification we have to seek a method of image features creation, those features can be used later to identify the image.

Many methods were proposed for image features extraction [16-22], but here in this paper we will take the concentration on Kmeans clustering method [23], [24].

The image features extraction method must characterize by the following [25], [26], [27]:

$\checkmark \quad$ Features size must be significantly small (minimizing the number of elements in the features array) [17], [18].

$\checkmark \quad$ The features must be unique for each image [19], [20], [21], this allow us to identify only one image based on the identified features [22].

$\checkmark \quad$ The features extraction time must be very small.

$\checkmark \quad$ The method of features extraction must be simple to implement and flexible to suit any image with any size.

$\checkmark \quad$ The proposed method of features extraction must be adjustable to change the number of elements in the features array.

K-means clustering method takes the input data set of values (points) \& group them into clusters as shown in fig $6 \& 7$ :
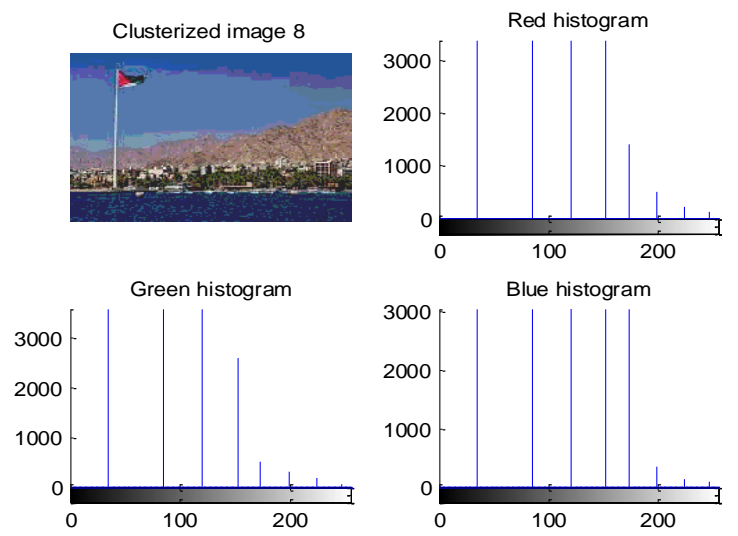

Figure 6: Clustering first image example to 8 clusters
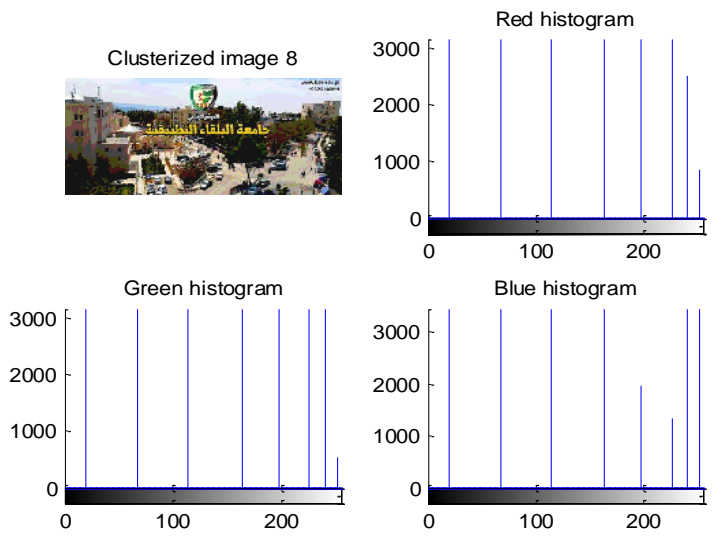

Figure 7: Clustering second image example to 8 clusters

Kmeans method is flexible method of features extraction because of the following:

$\checkmark \quad$ Number of clusters is variable (so the number of features is also variable).

$\checkmark \quad$ We can use the clusters centroids as features.

$\checkmark \quad$ We can use the number of points in each cluster as features.

$\checkmark \quad$ We can use the within clusters sums (WCS) as features.

The efficiency (minimum clustering time) depends on the size of the input data set to be Clusterized, table 1 shows the clustering time for various input data sets with various number of data values: 
International Journal of Advanced Research in Computer and Communication Engineering

Vol. 9, Issue 1, January 2020

Table 1: Clustering time for various input data sets

\begin{tabular}{|c|c|c|c|c|}
\hline Data size(elements) & 256 & 500 & 1000 & 2000 \\
\hline \multirow{3}{*}{$\begin{array}{c}\text { Centroids } \\
\text { (features) }\end{array}$} & $\mathbf{0 . 0 4 4 8}$ & $\mathbf{0 . 0 5 1 1}$ & $\mathbf{0 . 0 8 5 0}$ & $\mathbf{0 . 0 8 6 0}$ \\
\cline { 2 - 5 } & $\mathbf{0 . 1 5 2 8}$ & $\mathbf{0 . 1 7 2 6}$ & $\mathbf{0 . 2 3 2 4}$ & $\mathbf{0 . 2 6 3 7}$ \\
\cline { 2 - 5 } & $\mathbf{0 . 2 6 9 9}$ & $\mathbf{0 . 2 8 3 1}$ & $\mathbf{0 . 3 7 0 1}$ & $\mathbf{0 . 4 4 8 9}$ \\
\cline { 2 - 5 } & $\mathbf{0 . 3 9 2 4}$ & $\mathbf{0 . 3 9 1 9}$ & $\mathbf{0 . 4 9 6 6}$ & $\mathbf{0 . 5 7 0 6}$ \\
\cline { 2 - 5 } & $\mathbf{0 . 5 1 1 7}$ & $\mathbf{0 . 5 3 5 2}$ & $\mathbf{0 . 6 1 4 4}$ & $\mathbf{0 . 6 9 4 0}$ \\
\cline { 2 - 5 } & $\mathbf{0 . 6 3 8 4}$ & $\mathbf{0 . 6 8 4 7}$ & $\mathbf{0 . 7 3 0 0}$ & $\mathbf{0 . 7 8 9 1}$ \\
\cline { 2 - 5 } & $\mathbf{0 . 7 8 3 9}$ & $\mathbf{0 . 8 2 2 0}$ & $\mathbf{0 . 8 3 2 9}$ & $\mathbf{0 . 8 8 6 0}$ \\
\cline { 2 - 5 } & $\mathbf{0 . 9 2 9 5}$ & $\mathbf{0 . 9 4 2 1}$ & $\mathbf{0 . 9 4 0 3}$ & $\mathbf{0 . 9 6 8 2}$ \\
\hline Extraction time(s) & 0.016000 & 0.069000 & 0.076000 & 0.143000 \\
\hline
\end{tabular}

From table 1 we can notice the following points:

- The extracted features for each data set are unique.

- The extraction time increases when the size of the input data set increases, figure 8 shows how the extraction time depends on the input data set size:

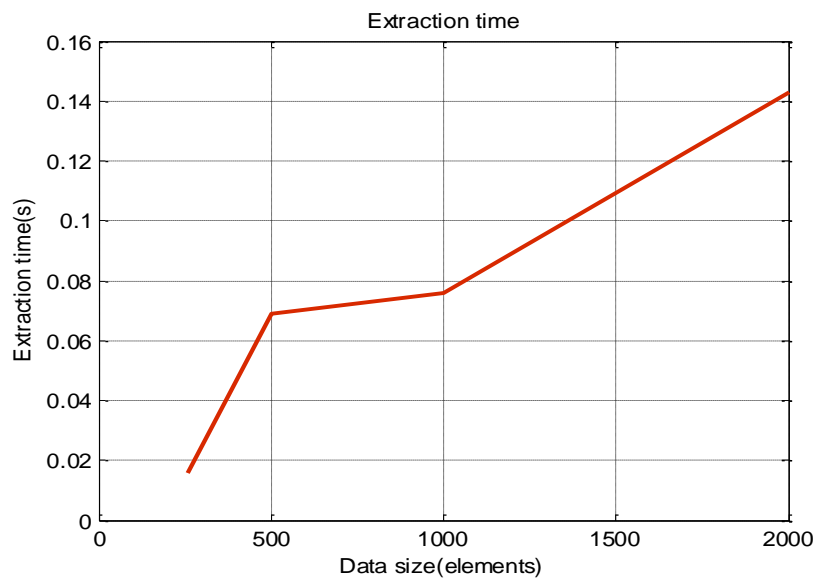

Figure 8: Relationship between extraction time and input data set size

\section{IMPLEMENTATION AND EXPERIMENTAL RESULTS}

To cluster the color image we have first must calculate the image histogram to be used as an input data set of the kmeans method of clustering. Getting the color image histogram can be achieved by performing one of the following procedures:

1. Getting the histogram for each color, and then adding the three histograms to get the total image histogram.

2. Converting the color image to gray one, and then calculate the histogram for the gray image.

3. Reshaping the matrix of the color from $3 \mathrm{D}$ matrix to $2 \mathrm{D}$ matrix, and then calculate the histogram for the obtained 2D matrix.

Figures 9 and 10 show the histograms calculated by these procedures.
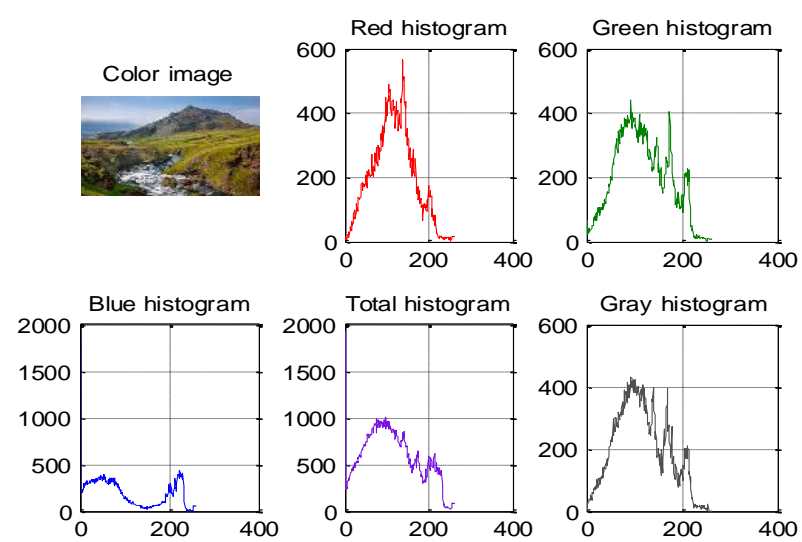

Figure 9: Colors histogram transformation 


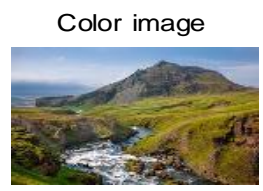

Reshaped image
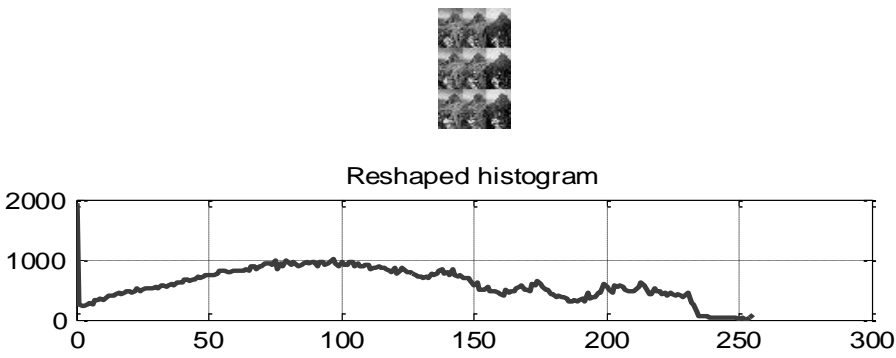

Figure 10: Reshaped histogram

Ten different color images were taken, for each color image we calculate the image histogram, the histogram then was used as an input data set for the clustering method, table 2 shows the results of implementation ( 8 clusters):

Table 2: Images features using image histogram

\begin{tabular}{|l|c|c|c|c|c|c|c|c|c|c|}
\hline Image & 1 & 2 & 3 & 4 & 5 & 6 & 7 & 8 & 9 & 10 \\
\hline \multirow{4}{*}{$\begin{array}{l}\text { Centroids } \\
\text { (features) }\end{array}$} & 49 & 10.3 & 39 & 653 & 186 & 9.8072 & 76 & 25.9 & 9.2432 & 0.0308 \\
\cline { 2 - 12 } & 94.6 & 30.9 & 97 & 2994 & 1548 & 31.3902 & 185 & 086.1 & 124.9444 & 0.1265 \\
\cline { 2 - 12 } & 134.7 & 72.1 & 321 & 4449 & 3412 & 71.1600 & 364 & 137.8 & 182.4082 & 0.2079 \\
\cline { 2 - 12 } & 300.6 & 179.3 & 550 & 7083 & 4959 & 114.5000 & 861 & 182.8 & 260.9231 & 0.2945 \\
\cline { 2 - 11 } & 472.1 & 666.3 & 1130 & 14048 & 7433 & 310.9444 & 2364 & 282.5 & 372.8667 & 0.8586 \\
\cline { 2 - 11 } & 718.3 & 1051 & 2047 & 17126 & 9130 & 424.7222 & 4630 & 357.1 & 511.5000 & 2.1672 \\
\cline { 2 - 11 } & 1268 & 2493 & 14651 & 20272 & 11283 & 535.8788 & 35413 & 5066 & 854.0000 & 5.1928 \\
\hline $\begin{array}{l}\text { Size } \\
\text { (pixel) }\end{array}$ & $\mathbf{1 5 0 8 4 9}$ & $\mathbf{7 7 9 7 6}$ & $\mathbf{5 1 8 4 0 0}$ & $\mathbf{5 1 4 0 8 0 0}$ & $\mathbf{4 3 2 6 2 1 0}$ & $\mathbf{1 2 2 2 6 5}$ & $\mathbf{5 1 8 4 0 0}$ & $\mathbf{1 5 0 9 7 5}$ & $\mathbf{1 5 1 3 5 3}$ & $\mathbf{6 1 1 9 2 5 6}$ \\
\hline $\begin{array}{l}\text { Extraction } \\
\text { Time(s) }\end{array}$ & $\mathbf{0 . 1 2 8 0}$ & $\mathbf{0 . 1 1 2 0}$ & $\mathbf{0 . 1 0 3 0}$ & $\mathbf{0 . 1 2 8 0}$ & $\mathbf{0 . 1 2 2 0}$ & $\mathbf{0 . 1 1 3 0}$ & $\mathbf{0 . 1 1 3 0}$ & $\mathbf{0 . 0 9 1 0}$ & $\mathbf{0 . 0 9 5 0}$ & $\mathbf{0 . 1 3 8 0}$ \\
\hline
\end{tabular}

Table 3 shows the results of clustering using a color image as an input data set for k_means method of clustering:

Table 4: Images features using image as an input data set

\begin{tabular}{|c|c|c|c|c|c|c|c|c|c|c|}
\hline Image & 1 & 2 & 3 & 4 & 5 & 6 & 7 & 8 & 9 & 10 \\
\hline \multirow{8}{*}{$\begin{array}{l}\text { Centroids } \\
\text { (features) }\end{array}$} & 8.5521 & 25.4997 & 2.5774 & 9.1410 & 25.1968 & 11.9923 & 1.2240 & 18.4911 & 5.0550 & 38.4423 \\
\hline & 31.2485 & 86.7116 & 28.9257 & 38.5558 & 55.6833 & 52.1211 & 31.8192 & 42.7221 & 24.3868 & 69.6645 \\
\hline & 58.3165 & 133.6779 & 52.9561 & 63.2538 & 79.0278 & 76.5654 & 59.5256 & 71.0862 & 47.4036 & 95.5554 \\
\hline & 89.2505 & 170.3380 & 76.5310 & 86.4431 & 102.9146 & 97.4980 & 85.6027 & 100.7797 & 76.0334 & 109.0075 \\
\hline & 122.2610 & 204.1441 & 105.2039 & 113.4587 & 130.1602 & 116.9805 & 110.3198 & 133.1483 & 108.9245 & 124.7367 \\
\hline & 163.5389 & 226.3049 & 136.3523 & 146.3849 & 161.7790 & 136.8949 & 139.5039 & 165.8910 & 143.0043 & 143.0428 \\
\hline & 201.1614 & 239.9785 & 170.8464 & 182.6851 & 196.0312 & 164.9973 & 173.9882 & 211.4594 & 176.5531 & 164.4444 \\
\hline & 236.8823 & 250.7539 & 212.9146 & 227.2600 & 239.1740 & 190.9049 & 241.6251 & 252.1470 & 231.0838 & 232.5371 \\
\hline $\begin{array}{l}\begin{array}{l}\text { Size } \\
\text { (pixel) }\end{array} \\
\end{array}$ & 150849 & 77976 & 518400 & 5140800 & 4326210 & 122265 & 518400 & 150975 & 151353 & 6119256 \\
\hline $\begin{array}{l}\text { Extraction } \\
\text { Time(s) }\end{array}$ & 1.6130 & 2.3120 & 9.5120 & 67.6070 & 47.2980 & 1.1360 & 5.7180 & 2.3050 & 2.3620 & 99.9350 \\
\hline
\end{tabular}

From tables 2 and 3 we can see the following facts:

$\checkmark$ Both input data sets gave different features, but each of them is a unique for a certain image.

$\checkmark$ Using image histogram increases the efficiency of clustering process by significantly decreasing the features extraction time, giving a big speed up as shown in table 3 
International Journal of Advanced Research in Computer and Communication Engineering

Vol. 9, Issue 1 , January 2020

Table 3: Results comparisons

\begin{tabular}{|c|c|c|c|}
\hline Image size & $\begin{array}{c}\text { Average features ex- } \\
\text { traction time(S) }\end{array}$ & $\begin{array}{c}\text { Average features extraction } \\
\text { time(S) using histogram }\end{array}$ & $\begin{array}{c}\text { Speedup of using } \\
\text { histogram }\end{array}$ \\
\hline Small image size<500k pixels & 3.5654 & 0.1143 & 31.1934 \\
\hline Greater than 1M pixels & 71.6133 & 0.1143 & 626.5381 \\
\hline
\end{tabular}

Kmeans clustering is a flexible method of data grouping, we can change the number of clusters to generate features array with different numbers of array elements, and also we can take the number of points in each cluster as a features or take within sums clusters as a features, table 4 and 5 shows the results of changing the number of clusters and the generated features using the number of points in each cluster.

Table 4: changing the number of clusters.

\begin{tabular}{|l|c|c|c|c|c|c|c|c|c|c|}
\hline \multicolumn{1}{|c|}{ Image } & 1 & 2 & 3 & 4 & 5 & 6 & 7 & 8 & 9 & 10 \\
\hline $\begin{array}{l}\text { Features } \\
\text { Number of } \\
\text { clusters=6 }\end{array}$ & $\mathbf{5 1 . 4}$ & $\mathbf{1 6 . 8}$ & $\mathbf{8 1}$ & $\mathbf{6 9 7}$ & $\mathbf{2 9 8}$ & $\mathbf{1 4 . 5 0 8 8}$ & $\mathbf{1 4 9}$ & $\mathbf{2 6 . 9}$ & $\mathbf{2 0 . 1 4 2 9}$ & $\mathbf{9 . 2 4 3 2}$ \\
\cline { 2 - 12 } & $\mathbf{1 1 1 . 2}$ & $\mathbf{6 6 . 5}$ & $\mathbf{3 3 1}$ & $\mathbf{3 3 9 8}$ & $\mathbf{2 7 2 4}$ & $\mathbf{6 4 . 4 4 4 4}$ & $\mathbf{3 6 2}$ & $\mathbf{9 8 . 1}$ & $\mathbf{9 7 . 6 9 0 5}$ & $\mathbf{1 3 6 . 4 7 4 7}$ \\
\cline { 2 - 12 } & $\mathbf{3 0 5 . 4}$ & $\mathbf{6 3 7 . 6}$ & $\mathbf{7 9 9}$ & $\mathbf{1 0 4 7 9}$ & $\mathbf{6 7 9 6}$ & $\mathbf{2 4 8 . 3 8 8 9}$ & $\mathbf{1 3 0 6}$ & $\mathbf{2 4 7}$ & $\mathbf{2 2 2 . 5 1 5 2}$ & $\mathbf{3 2 3 . 2 7 5 9}$ \\
\cline { 2 - 12 } & $\mathbf{5 9 2 . 7}$ & $\mathbf{1 0 5 1}$ & $\mathbf{1 3 6 1}$ & $\mathbf{1 4 6 0 6}$ & $\mathbf{8 7 5 0}$ & $\mathbf{3 7 7 . 0 0 0 0}$ & $\mathbf{3 1 1 0}$ & $\mathbf{3 3 6 . 6}$ & $\mathbf{3 0 0 . 0 4 6 5}$ & $\mathbf{5 1 1 . 5 0 0 0}$ \\
\cline { 2 - 11 } & $\mathbf{1 2 6 8}$ & $\mathbf{2 4 9 3}$ & $\mathbf{1 4 6 5 . 1}$ & $\mathbf{1 9 4 2 9}$ & $\mathbf{1 1 1 7 9}$ & $\mathbf{5 2 6 . 8 4 2 1}$ & $\mathbf{3 5 4 1 3}$ & $\mathbf{5 0 6 6 0}$ & $\mathbf{3 8 4 . 3 0 6 1}$ & $\mathbf{8 5 4 . 0 0 0 0}$ \\
\hline \multirow{4}{*}{$\begin{array}{l}\text { Features } \\
\text { Number of } \\
\text { clusters=4 }\end{array}$} & $\mathbf{1 0 4 . 1 7 6 5}$ & $\mathbf{2 5 . 5}$ & $\mathbf{2 3 2}$ & $\mathbf{2 3 3 9}$ & $\mathbf{4 8 0}$ & $\mathbf{2 0 . 1 7 9 1}$ & $\mathbf{2 2 9}$ & $\mathbf{6 5 . 4}$ & $\mathbf{3 2 . 1 5 8 7}$ & $\mathbf{9 . 2 4 3 2}$ \\
\cline { 2 - 11 } & $\mathbf{1 9 6 . 5 5 2 4}$ & $\mathbf{2 3 0 . 6}$ & $\mathbf{6 8 6}$ & $\mathbf{7 6 2 7}$ & $\mathbf{4 7 8 3}$ & $\mathbf{1 2 1 . 4 2 5 5}$ & $\mathbf{1 0 0 0}$ & $\mathbf{1 8 3 . 2}$ & $\mathbf{1 4 2 . 8 4 4 2}$ & $\mathbf{1 4 8 . 2 1 4 9}$ \\
\cline { 2 - 11 } & $\mathbf{3 3 8 . 1 3 6 4}$ & $\mathbf{8 9 9 . 9}$ & $\mathbf{1 2 5 2}$ & $\mathbf{1 3 6 2 8}$ & $\mathbf{7 0 9 6}$ & $\mathbf{3 2 0 . 0 6 0 6}$ & $\mathbf{2 7 4 1}$ & $\mathbf{2 9 1 . 7}$ & $\mathbf{2 6 7 . 1 2 0 7}$ & $\mathbf{2 9 9 . 7 1 5 9}$ \\
\cline { 2 - 11 } & $\mathbf{8 2 8 . 2 0 0 0}$ & $\mathbf{2 4 9 3}$ & $\mathbf{1 4 6 5 1}$ & $\mathbf{1 9 3 2 9}$ & $\mathbf{1 0 7 3 8}$ & $\mathbf{5 1 8 . 6 1 9 0}$ & $\mathbf{3 5 4 1 3}$ & $\mathbf{5 0 6 6}$ & $\mathbf{3 7 5 . 9 8 2 8}$ & $\mathbf{5 8 0 . 0 0 0 0}$ \\
\hline
\end{tabular}

Table 5: Number of points in each cluster as a features

\begin{tabular}{|c|c|c|c|c|c|c|c|c|c|c|}
\hline Image & 1 & 2 & 3 & 4 & 5 & 6 & 7 & 8 & 9 & 10 \\
\hline \multirow{8}{*}{$\begin{array}{l}\text { Features } \\
\text { (number of } \\
\text { points in each } \\
\text { cluster) }\end{array}$} & 57 & 26 & 49 & 11 & 47 & 83 & 53 & 31 & 26 & 36 \\
\hline & 49 & 1 & 33 & 24 & 49 & 18 & 1 & 1 & 27 & 57 \\
\hline & 4 & 107 & 4 & 19 & 38 & 18 & 33 & 44 & 47 & 53 \\
\hline & 32 & 6 & 36 & 58 & 31 & 18 & 5 & 31 & 30 & 32 \\
\hline & 7 & 27 & 28 & 13 & 11 & 33 & 61 & 52 & 31 & 33 \\
\hline & 27 & 7 & 83 & 30 & 26 & 25 & 72 & 43 & 19 & 8 \\
\hline & 1 & 7 & 1 & 11 & 11 & 20 & 30 & 18 & 38 & 2 \\
\hline & 79 & 75 & 22 & 90 & 43 & 41 & 1 & 36 & 38 & 35 \\
\hline
\end{tabular}

\section{CONCLUSION}

K-means clustering method is a suitable and flexible method used for color image features extraction, using color image histogram increases the clustering method of clustering by speeding up the process of color image features extraction.

Based on the obtained experimental results we can raise the following facts:

- $\quad$ Each obtained color image features are unique, and they can be easily used to identify the image.

- The number of elements in the features array can be variable, because it is very simple to change the number of clusters.

- Clustering is a flexible method, we can select the clusters centroids, or the number of points in each cluster, or the within clusters sums as a features.

\section{REFERENCES}

[1]. Musbah J. Aqel, Ziad A. Alqadi, Ibraheim M. El Emary, Analysis of Stream Cipher Security Algorithm, Journal of Information and Computing Science, Vol. 2, No. 4, 2007, pp. 288-298.

[2]. Ziad Al-Qadi, Musbah Aqel, Performance analysis of parallel matrix multiplication algorithms used in image processing, World Applied Sciences Journal, v. 6, issue 1, pp. 45-52, 2009.

[3]. Jamil Al-Azzeh, Bilal Zahran, Ziad Alqadi, Belal Ayyoub, Muhammed Mesleh, A Novel Based On Image Blocking Method To EncryptDecrypt Color image, International Journal on Informatics Visualization, v. 3, issue 1, pp. 86-93, 2019.

[4]. Khaled M Matrouk, Haitham A Alasha'ary, Abdullah I Al-Hasanat, Ziad A Al-Qadi, Hasan M Al-Shalabi, Investigation and Analysis of ANN Parameters, European Journal of Scientific Research, v. 121, issue 2, pp. 217-225, 2014.

[5]. Ziad A. AlQadi Amjad Y. Hindi, Majed O. Dwairi, A Novel Technique for Data Steganography, Engineering, Technology \& Applied Science Research, v. 9, issue 6, pp. 4942-4945, 2019. 


\section{International Journal of Advanced Research in Computer and Communication Engineering}

Vol. 9, Issue 1 , January 2020

[6]. J Al-Azzeh M Abuzalata, Ziad Alqadi, Modified Inverse LSB Method for Highly Secure Message Hiding, International Journal of Computer Science and Mobile Computing, v. 8, issue 2, pp. 93-103, 2019.

[7]. Majed O Al-Dwairi, Ziad A Alqadi, Amjad A Abujazar, Rushdi Abu Zneit, Optimized true-color image processing, World Applied Sciences Journal, v. 8, issue 10, pp. 1175-1182, 2010.

[8]. Jamil Al Azzeh, Hussein Alhatamleh, Ziad A Alqadi, Mohammad Khalil Abuzalata, Creating a Color Map to be used to Convert a Gray Image to Color Image, International Journal of Computer Applications, v. 975, pp. 8887, 2016.

[9]. Jihad Nader, Ziad A. A. Alqadi, Bilal Zahran, Analysis of Color Image Filtering Methods, International Journal of Computer Applications, v. 174, issue 8, pp. 12-17, 2017.

[10]. Dr. Ziad Alqadi, Akram Mustafa, Majed Alduari, Rushdi Abu Zneit, True color image enhancement using morphological operations, International review on computer and software, v. 4, issue 5, pp. 557-562, 2009.

[11]. Bilal Zahran Belal Ayyoub, Jihad Nader, Ziad Al-Qadi, Suggested Method to Create Color Image Features Victor, Journal of Engineering and Applied Sciences, v. 14, issue 1, pp. 2203-2207.

[12]. Ziad Alqadi, A Modified Lbp Method to Extract Features from Color Images, Journal of Theoretical and Applied Information Technology, v. 96, issue 10, pp. 3014-3024.

[13]. Ziad AlQadi, Hussein M Elsayyed, Window Averaging Method to Create a Feature Victor for RGB Color Image, International Journal of Computer Science and Mobile Computing, v. 6, issue 2, pp. 60-66, 2017.

[14]. Qazem Jaber Ziad Alqadi, Jamil azza, Statistical analysis of methods used to enhance color image histogram, XX International scientific and technical conference, 2017.

[15]. Ziad Alqadi, Bilal Zahran, Qazem Jaber, Belal Ayyoub, Jamil Al-Azzeh, Ahmad Sharadqh, Proposed Implementation Method to Improve LSB Efficiency, International Journal of Computer Science and Mobile Computing, v. 8, issue 3, pp. 306-319, 2019.

[16]. Ziad Alqadi, Bilal Zahran, Qazem Jaber, Belal Ayyoub, Jamil Al-Azzeh, Enhancing the Capacity of LSB Method by Introducing LSB2Z Method, International Journal of Computer Science and Mobile Computing, v.8, issue 3, pp. 18, 2019.

[17]. Dr Rushdi S Abu Zneit, Dr Ziad AlQadi, Dr Mohammad Abu Zalata, A Methodology to Create a Fingerprint for RGB Color Image, IJCSMC, v. 6, issue 1, pp. 205-212, 2017

[18]. Ziad Alqadi, Bilal Zahran, Jihad Nader, Estimation and Tuning of FIR Lowpass Digital Filter Parameters, International Journal of Advanced Research in Computer Science and Software Engineering, v. 7, issue 2, pp. 18-23, 2017.

[19]. Musbah J Aqel, Ziad ALQadi, Ammar Ahmed Abdullah, RGB Color Image Encryption-Decryption Using Image Segmentation and Matrix Multiplication, International Journal of Engineering and Technology, v. 7, issue 13.3, pp. 104-107, 2018.

[20]. Ziad AlQadi, Hussein M Elsayyed, Window Averaging Method to Create a Feature Victor for RGB Color Image, International Journal of Computer Science and Mobile Computing, v. 6, issue 2, pp. 60-66, 2017.

[21]. R Abu Zneit, Ziad AlQadi, M Abu Zalata, A Methodology to Create a Fingerprint for RGB Color Image, International Journal of Computer Science and Mobile Computing, v. 16, issue 1, pp. 205-212, 2017.

[22]. Mohammed Ashraf Al Zudool, Saleh Khawatreh, Ziad A. Alqadi, Efficient Methods used to Extract Color Image Features, IJCSMC, v. 6, issue 12, pp. 7-14, 2017.

[23]. Ahmad Sharadqh Naseem Asad, Ismail Shayeb, Qazem Jaber, Belal Ayyoub, Ziad Alqadi, Creating a Stable and Fixed Features Array for Digital Color Image, IJCSMC, v. 8, issue 8, pp. 50-56, 2019.

[24]. Ahmad Sharadqh Jamil Al-Azzeh , Rashad Rasras, Ziad Alqadi, Belal Ayyoub, Adaptation of matlab K-means clustering function to create Color Image Features, International Journal of Research in Advanced Engineering and Technology, v.5, iss.2, pp. 10-18, 2019.

[25]. Yousf Eltous Ziad A. AlQadi, Ghazi M. Qaryouti, Mohammad Abuzalata, Analysis of Digital Signal Features Extraction Based on Kmeans Clustering, International Journal of Engineering Technology Research \& Management, v. 4, issue 1, pp. 66-75, 2020.

[26]. Prof. Yousif Eltous, Dr. Ghazi M. Qaryouti, Prof. Mohammad Abuzalata, Prof. Ziad Alqadi, Evaluation of Fuzzy and C_mean Clustering Methods used to Generate Voiceprint, IJCSMC, v. 9, issue 1, pp. $75-83,2020$.

[27]. Jihad Nader Ismail Shayeb, Ziad Alqadi, Analysis of digital voice features extraction methods, International Journal of Educational Research and Development, v. 1, issue 4, pp. 49-55, 2019 